\title{
Factors Influencing Tutors' Use of ICT: a Case Study of Mukuju Core Primary Teachers' College
}

\author{
Alfred Joe Ogot ${ }^{1, *} \&$ Lucy Dora Akello ${ }^{1}$
}

\section{(C) Uganda Martyrs University}

\begin{abstract}
This study examined the factors influencing the integration of ICTs in teaching/learning at Mukuju Core Primary Teachers' College. Data were collected from staff and students at the College-using questionnaires and focus group discussions. The findings were that tutors' and students' conversance with ICTs, attitude towards the technologies and access to the internet influenced the former's integration of ICTs in teaching/learning. Therefore, it is recommended that the tutors, and their students, be trained/retrained in the use of ICTs and that the College's connectivity to the internet is improved.
\end{abstract}

Keywords $\cdot$ ICT $\cdot$ e-learning $\cdot$ Technology adoption $\cdot$ Teacher education

Facteurs Influençant l'Usage de Technologie and Communication Informatique (TCI) : Cas de l'Institut Supérieur de Pédagogie Primaire de Mukuju · Résumé - Cette étude a examiné les facteurs influençant l'intégration de TCIs dans la pédagogielenseignement à l'Institut Supérieur de Pédagogie Primaire de Mukuju. Les données ont été collectées de la part du personnel et étudiants de cet institut supérieur, usant les questionnaires et discussions dans de groupes focaux. Les résultats ont montrée que la familiarité des instructeurs et étudiants avec les TCIs, l'attitude envers les technologies ainsi que l'accès à l'internet ont influencé l'intégration de TCIs dans la pédagogielenseignement. C'est pourquoi, il est recommandé que les instructeurs ainsi que leur étudiants soient formés/reformés dans l'usage de TCIs et que la connexion du réseau internet à cet institut supérieur soit améliorée. Mots Clé $\cdot$ TCI - Enseignement par Informatique (IEnseignement) $\cdot$ adoption technologique $\cdot$ éducation pédagogique

\section{Introduction}

The purpose of this paper is to share the findings of a study on factors affecting the use of Information and Communication Technologies (ICTs) by tutors and students. Furthermore, the paper aims to create a platform for promoting the use of ICT resources for teaching and learning in educational institutions. We shall specifically report the methodology, finding, discussion, conclusions and recommendations of the study.

Information and communications technology (ICT) has transformed the means by which we inform ourselves, remain up to date with world events, and further our learning. We now acquire and access information in ways fundamentally different from the pre-ICT era. These new ways of

\footnotetext{
${ }^{1}$ Uganda Martyrs University, ${ }^{*}$ Corresponding author: ogotalfred@gmail.com
}

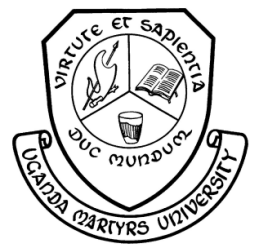


acquiring and accessing information are also having an increasingly significant impact on learning and teaching.

Education systems around the world are under increasing pressure to use the new ICTs to teach students the knowledge and skills they need in the new millennium. As noted in the UNESCO World Education Report, Teachers and Teaching in a Changing World (UNESCO, 1998), the young generation is entering a world that is changing in all spheres: scientific and technological, political, economic, social, and cultural. The emergence of the 'knowledge-based' society, the report continues, is changing the global economy and the status of education. These changes have brought about a new educational paradigm, which, according to Adeya (2001), requires that students should be taught how to think critically and independently, exercise appropriate judgment, collaborate with others, adapt to new and uncertain situations, identify problems and then solve them, and synthesise old information with new. This paradigm shift has, by and large, generated new types of learners, new process of learning, which in turn has contributed to the changed roles of teachers from the conventional ones of instructing learners to that of facilitating learners to construct knowledge.

Consequently, teacher education institutions are challenged to either assume a leadership role in the transformation of education or be left behind in the swirl of rapid technological change (Resta, 2002). To overcome this challenge requires both a change in the traditional view of the learning process and an understanding of how the new digital technologies can create new learning environments in which students are engaged learners, and able to take greater responsibility for their own learning.

In view of this, there have been numerous efforts and resources directed at improving teachers' knowledge and skills in using ICT for teaching and learning. For instance, a survey of ICT and Education in Africa by Farrell (2007) reported that Connect-ED used technology to enhance learning and teaching through the creation of multifaceted approaches to integrating media and computers in the Primary Teachers' Colleges (PTCs). Similarly, use of ICT for teaching and learning was introduced in Ugandan Primary Teachers' Colleges in 2000 through Connect-ED project. The Connect-ED project in Uganda, according to Jung, (2005), was designed to improve professional development for primary school teachers. This was accomplished by setting up Education Technology Centres at Bushenyi, Ndegeya, Shimoni, Kibuli, Mukuju, Soroti, Gulu and Canon Lawrence, Boroboro PTCs, (Farrell, 2007), with the view to increasing access, availability, and provision of relevant and quality learning materials and support for teacher professional development.

However, the limited use of ICT in teacher education has made combining new technologies with effective pedagogy a daunting task for both initial teacher training and in-service training institutions (Jung, 2005). Uganda is not exceptional to this challenge. Uganda is challenged by the most basic issues: poorly developed ICT infrastructure, high bandwidth costs, an unreliable supply of electricity, and a general lack of resources to meet a broad spectrum of needs as it adopts ICT in education (Farrell, 2007).

\section{Methodology}

A case study research design was adapted for the study. The study was carried out in Mukuju Core PTC in Tororo, Uganda. Purposive sampling was used to select the college and the district for the study. Mukuju Core PTC was selected because it was the only educational institution in Tororo which trains primary school teachers besides being the only one which was equipped with computer-assisted teacher training laboratories and resource centres and its staff trained to integrate ICT into the teaching strategies of Primary Teacher's College (PTC). It also offers outreach support to primary schools in a wider area covering Busia, Butaleja, and Tororo districts. A sample of 153 participants consisted of administrators, pre-service tutors, outreach tutors, and student-teachers distributed as follows: 3 college administrator respondents, 14 pre-service tutor respondents, 7 outreach tutor respondents and 129 student-teacher respondents. Such a sample size was chosen to 
ensure diversity in order to make the research findings applicable to the whole population; representativeness so as to fulfil the questions the research addressed; and it was the sample population that was deemed to have idea of the topic being investigated. The researcher used questionnaires and focused group discussion to collect data... This was because the researcher was mainly concerned with facts, opinions and attitudes which could best be collected through the use of questionnaire and focused group discussion techniques (Bell, 1993; Touliatos \& Compton, 1988).

\section{Findings and Discussion}

The first objective of this study was to assess the level of ICT use in teaching/learning by tutors and student-teachers. Data analysis and interpretation revealed that: tutors and student teachers considered themselves not competent in the use of the basic computer applications for teaching and learning, they accessed ICT in the computer laboratory and in classroom, and that they used word processing more than any other computer applications. These findings indicated that tutors and student teachers could not apply computer applications like word processing, spreadsheets, presentation tools and internet search in teaching and/or learning process, and that they could not access ICT elsewhere as they did in the computer laboratory. This could be attributed to a wide range of factors namely difficulties in using software/hardware, need for more technical support, insufficient access to the resources, and insufficient technical resources. The degree of presence of the above factors has affected the adoption and integration of ICT for teaching and learning.

The second objective of this study was to investigate the benefits of using ICT by tutors and student-teachers for teaching and learning. This finding indicated that ICT helped tutors make lesson plans richer, helped them to explain things more clearly to students, helped them to cater for individual differences, facilitated assessing and grading students, enabled tutors interact with colleagues from other colleges and/or countries, and that it enabled them improve on their professional skills. These findings complement observations by Cox et al. (2003) that ICT can make an important contribution to schools, for instance, helping in the teaching and delivery of the curriculum in a number of ways such as helping tutors make the lesson more interesting; enabling tutors explain things more clearly to learners; and using it across the curriculum.

The third objective of this study was to find out the factors that affect tutors' and studentteachers' use of ICT. Data analysis and interpretation revealed that lack of knowledge on the new tools and technologies of education was the key factor affecting the integration of ICT in teaching and learning. This finding indicated that lack of training and retraining opportunities; unreliable power supply; inadequate number of computers; lack of motivation; scare of computer-related health problems; and expensive computer accessories were the most likely contributing factors to lack of knowledge on the new tools and technologies of education.

In a related manner, studies by Suduc (2007) revealed a relationship between the number of hours of computer technology training and percentage of time tutors use technology themselves and with their student teachers. For instance, Jager \& Lokman (1999) in their Dutch report reported that the major concern of European ministries of education was that teachers did not receive the appropriate training in ICT use. For that matter, Lau and Sim (2008) recommended that training should be offered to teachers on a continuous, rather than a one-off basis so that their IT knowledge is upgraded over time.

The fourth objective of this study was to suggest how to enhance integration of computer knowledge in teaching and learning. Data analysis and interpretation revealed that student teachers, tutors and administrators needed to develop positive attitude towards learning and using computers; to integrate computer in teaching and learning; and to teach or acquire knowledge and skills on computer application to teaching and learning. This could be compounded by the fact that:

The world of teaching is more conservative - its benefits were established by a sector of society

where competition and growth were not essential for survival. The schools, colleges and 
universities do not generally adopt the same thrusting approach in their affairs as do business and industry (Chauhan, 1983).

These findings indicated that the key inputs required in order to enhance the integration of computer knowledge into the tutors' teaching and learning were knowledge and skills, appropriate number of computers, change of mindset to come out of comfortable zones, and willingness to integrate computer knowledge into the tutors' teaching and learning.

The overall task of Connectivity for Education Development, (Connect-ED), as reported by Cisler and Yokam (2003), was to integrate computers into the teaching methods of Primary Teacher's College (PTC). However, respondents' concern over tutors' pedagogical difficulties to integrate technology in instruction concurred with Cox et al. (1999); and Zhao and Cziko (2001) report on an international survey of teachers' perceived obstacles to using ICT. Therefore, colleges and the Ministry of Education and Sport should promote the acquisition of knowledge and skills that make possible continuous learning over the lifetime (Thornburg, 2000).

\section{Conclusions and Recommendations}

In view of these findings the study concluded that a number of interrelated factors affect the integration of ICT in teaching and learning endeavours. This implies that tutors and student teachers had knowledge of new tools and technologies of education but not sufficient enough to enable them integrate ICT in teaching and learning; they accessed ICT in the computer laboratory and in classroom mostly; they used word processing more than all other ICT applications; they experienced attitudinal setbacks to the use of ICT, and they derived benefits from using ICTs and therefore, considered it valuable.

It is against this background that the following recommendations are made. First, in regard to tutors' and student teachers' level of knowledge and skill in the use of new technologies of education, and their use of word processing more than the other applications, the researchers adopted recommendations fronted by tutors, thus, students should be taught computer and how to use it as a medium of teaching and learning practically.

Through in-service training tutors and teachers have the opportunity to improve and develop their professional knowledge and skills. Special interest should be given to the information communication and technology area due to the increasing use of new technologies and Internet in education and the demand it exerts on the education system. In Uganda, like all other countries, the priority is to promote problem-solving, critical thinking, collaboration, and construction of knowledge using the new technologies. The Teacher Development and Management System (TDMS) structures provide a great opportunity for the teachers to receive support on technical and pedagogical knowledge related to the use of ICT as a medium for teaching and learning. Trainings can be carried out at college, at Co-coordinating Centres and/or at outreach school sites by tutors, teachers and student teachers who have knowledge on computer, and through self initiative such as enrolling in computer training institutions.

Secondly, the PTC administration and the Ministry of Education and Sports should address the issue of limited access to ICT by increasing the number of computers in PTCs as suggested by tutors. This can be done by installing computers in the college library, in subject rooms, and offices.

Thirdly, although the study established that tutors derived benefits from using ICTs and therefore, considered it valuable, the Ministry of Education and Sports, Kyambogo University and PTC administration need to cease, promote and reinforce this opportunity by strengthening and/or operationalising the ICT policy, and integrating it into the teacher education curriculum. Furthermore, Kyambogo University and its affiliate institutions should teach ICT as an applied subject to prepare their products for its use as a medium for teaching and learning.

Fourthly, student teachers should be able to access and use computers and their accessories during their training. There is need to create new ways of looking at things in this era of dwindling resources. It is the opinion of the researcher that new partnerships be created between the private sector and government in order to meet this critical need. For instance, involving individuals and companies in the private sector in providing computers and computer training, will be in the 
interests of both the government and the private sector to develop their skills and experience and look for ways that both can work together.

In conclusion, we need to move rapidly on all fronts because the world is changing even as this paper is being presented. Globalization and technological change have created a new global economy "powered by technology, fuelled by information and driven by knowledge" (US Department of Labour, 1999). Information and communication technology has enormous potential that can only be realized if all of our "millennium children" get equipped with knowledge and skills that will enable them participate favourably in the information-rich, knowledge society. It is, therefore, critical that our governments, and educational institutions, alike, should move faster to embrace ICT so that we can have the modern time competent teachers to be able to impart knowledge and skills of modern times.

\section{References}

Adeya, C. N., 2001. Information and Communication Technologies in Africa: A Review and Selective Annotated Bibliography 1990-2000. Oxford: INASP.

Chauhan S.S. 1983. Innovations in Teaching - Learning Process. (2 ${ }^{\text {nd }}$ Ed.) New Delhi: Vikas Publishing House PVT LTD.

Cisler, S. and Yokam, K. 2003. Connect-ED Evaluation (Uganda). Prepared for USAID.

Cox, M. et al., 1999. What Factors Support or Prevent Teachers from Using ICT in the Primary Classrooms. Paper presented at the British Educational Research Association Annual Conference [Education-line Online] Available at: http://www.leeds.ac.uk/educol/documents/00001304.htm [Viewed 18-8-2007]

Cox, M. et al., 2003. ICT and pedagogy. A review of the research literature. ICT in Schools Research and Evaluation Series - No18 A report to the DfES [Online] Available at: http://www.becta.org.uk/research [Viewed: 21-4-2010]

Educational Research. Lahti, Finland 22 - 25 September 1999. [e-paper] Available at: http://www.leeds.ac.uk/educol/documents/00001201.htm [Viewed 8-3-2010]

Farrell, G., 2007. ICT in Education in Uganda. Survey of ICT and Education in Africa: Uganda Country Report. [Online] Available at: www.infodev.org [Viewed 9-12-2009]

Jung, I., 2005. ICT-Pedagogy Integration in Teacher Training: Application Cases Worldwide. Educational Technology \& Society, 8 (2), 94-101. [e-journal] Available at: Division of Education, International Christian University. [Viewed 20-2-2010]

Lau, B. T., and Sim, C. H., 2008. Exploring the extent of ICT adoption among Secondary school teachers in Malaysia. International Journal of Computing and ICT Research, Vol. 2, No. 2, December 2008 [Online] Available at: http://www.ijcir.org/volume2-number2/article 3.pdf. [Viewed 20-2-2010]

Suduc, A.M., 2007. ICT in Education: Reflections and Perspectives. FISTE - A Future Way for InService Teacher Training Across Europe. Bucharest, June 14-16, 2007.

Touliatos, J. S. and Compton, N. H., 1988. Research Methods in Human Ecology and Home Economics. Iowa State University Press/AMES.

US Department of Labour, 1999. Future work-Trends and Challenges for Work in the 21st Century. Quoted in EnGauge, "21st Century Skills," Available at: http://www.ncrel.org/engauge/skills/21skills.htm [Viewed: 31-5- 2009]

Zhao and Cziko, 2001. Teacher adoption of technology: A perceptual control theory perspective. Journal of Technology and Teacher Education. v9. 5-30.

\section{Author Biography}

Ogot Owino Joe Alfred is tutor at Rubengera Teacher Training College in Kibuye, Rwanda. His research interests include pedagogical innovation and second language learning.

Akello Lucy Dora is a lecturer at the Faculty of Education, Uganda Martyrs University. She is also the Coordinator of Quality Assurance Coordinator at the University. Her research interests focus on language development and pedagogy. 
